\title{
Políticas e poéticas da vida urbana: um exercício de etnografia visual

\author{
Pedro Jaime Coelho Jr.
}

\author{
"Na verdade, bom mesmo é andar a pé, \\ de olho no que cada dobrar de esquina nos revela. \\ É a velocidade ideal para descobrir as coisas" \\ Cristiano Mascaro \\ [Entrevista publicada em Olhares refletidos, de \\ Joaquim Paiva (Rio de Janeiro: Dazibao, 1989, \\ p. 206).]
}

Este ensaio apresenta o resultado parcial de uma pesquisa fotoetnográfica sobre o espaço urbano. Flanando pela vida cotidiana de diferentes metrópoles, procuro interpretar os diá-

\begin{abstract}
logos que os sujeitos tecem nas suas interaçôes com os outros e com as intervençóes urbanas. Meu olhar se dirige para as faces política e poética das cidades. Faces reveladas em cenas que traduzem a pressa e a indiferença, mas também a cumplicidade e a sutileza. As imagens foram feitas entre 2005 e 2007 nas ruas de Salvador, Rio de Janeiro, Belo Horizonte, São Paulo e Buenos Aires. Caminhando por essas urbes, fui escrevendo esse texto de antropologia visual. Um texto provisório, aberto a múltiplas reinterpretaçôes.
\end{abstract}

autor Pedro Jaime Coelho Jr.

Professor do Centro de Ciências Sociais e Aplicadas/Universidade Presbiteriana Mackenzie Doutorando em Ciência Social (Antropologia Social)/USP

Recebido em 12/02/2007

Aceito para publicação em 22/10/2007 
I72 | Pedro Jaime Coelho Jr.

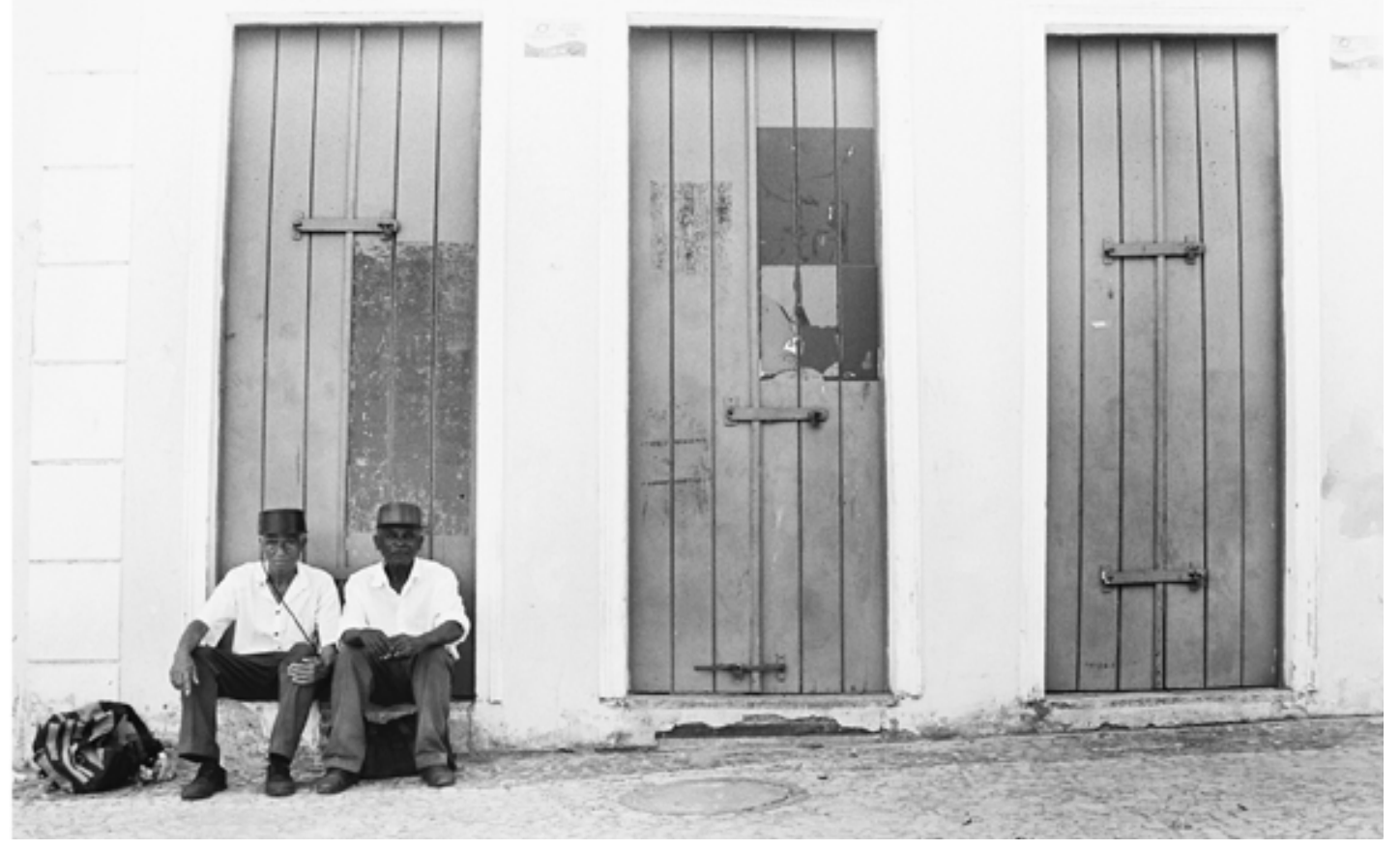

1. Cumplicidade / Salvador-BA

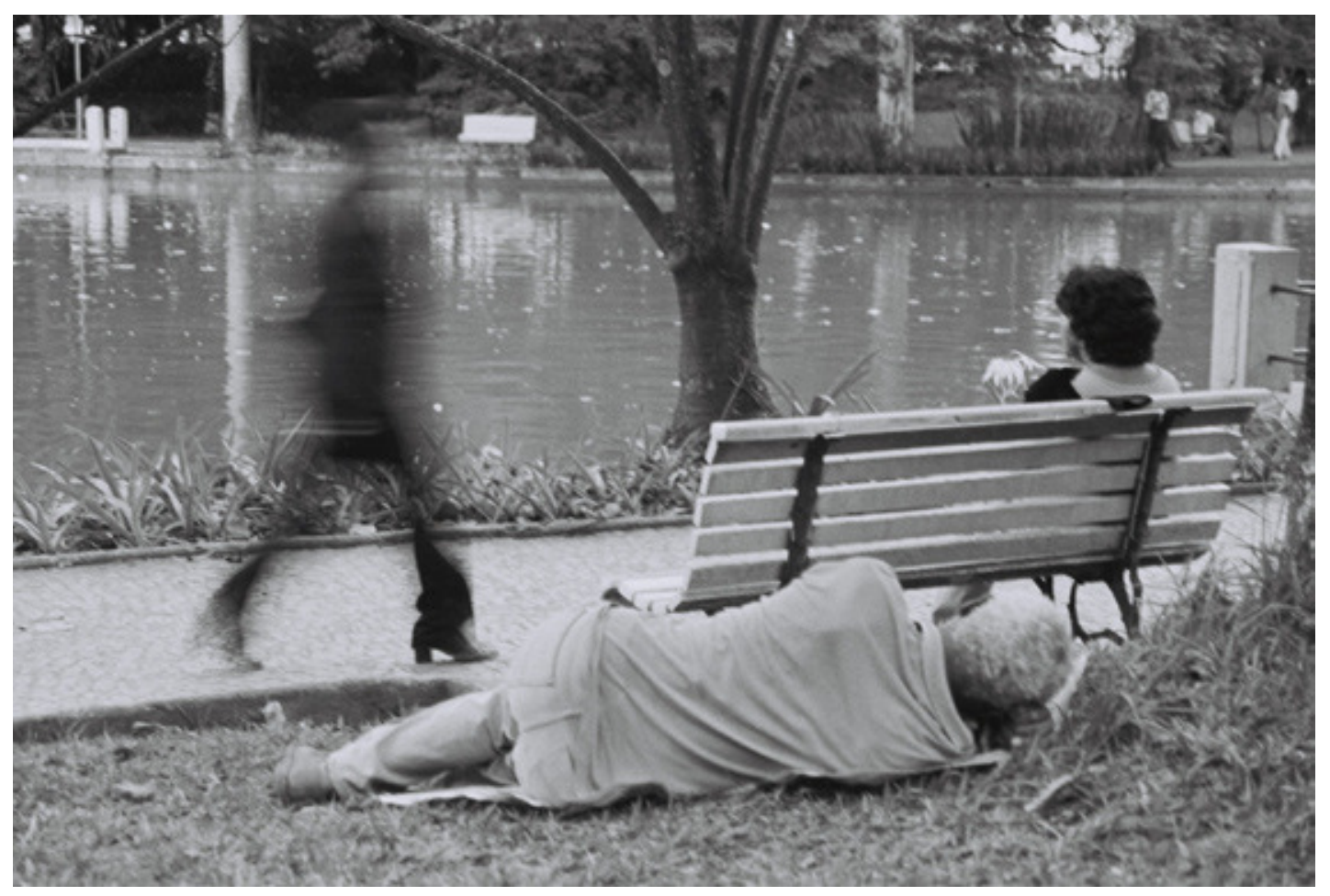

2. Desencontros / Belo Horizonte-MG

cadernos de campo, São Paulo, n. 16, p. 171-175, 2007 
Políticas E POÉTICAS DA VIDA URbaNa $\mid$ I73

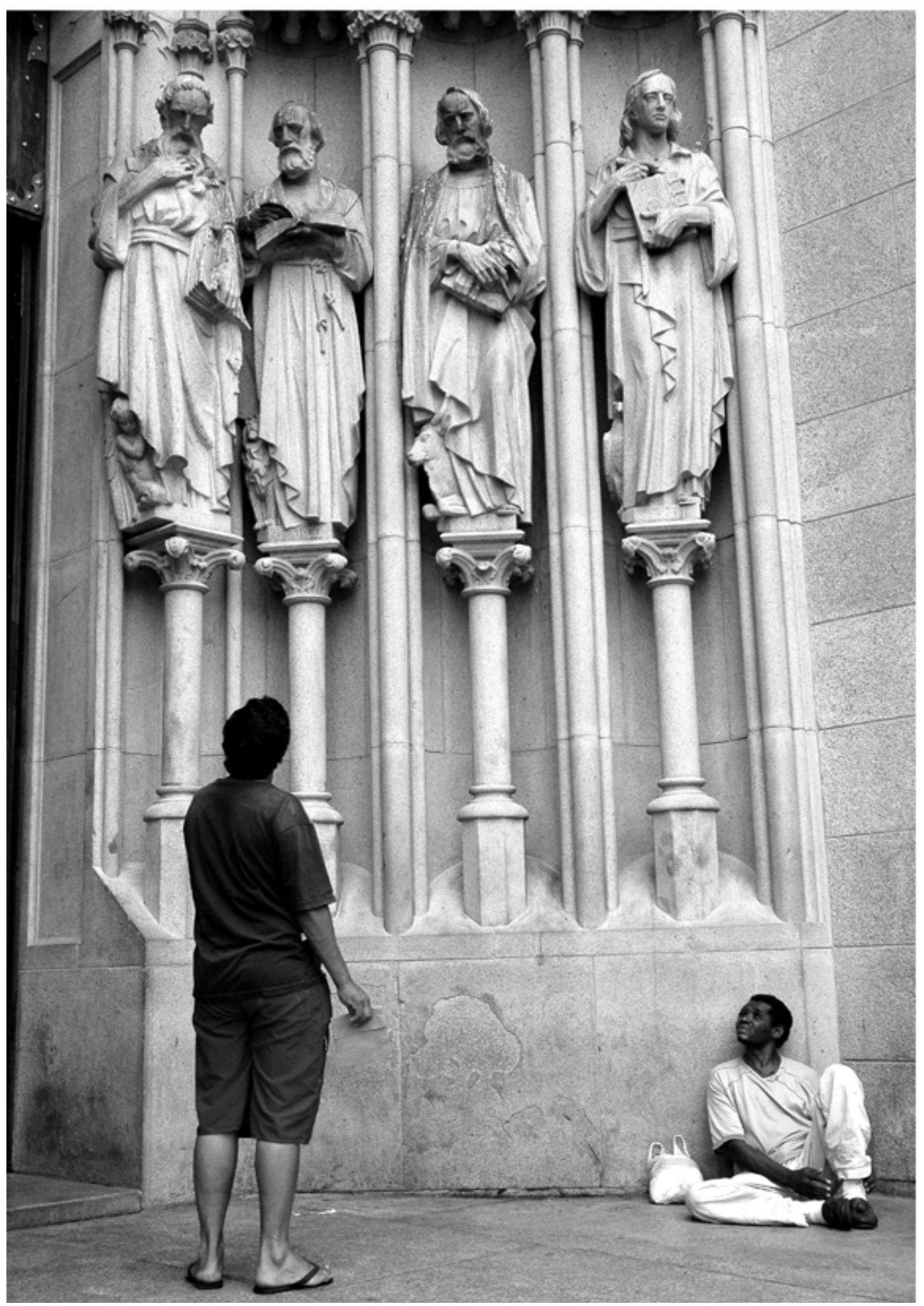

3. Olhares cruzados / São Paulo-SP

cadernos de campo, São Paulo, n. 16, p. 171-175, 2007 
I74 | Pedro Jaime Coelho Jr.

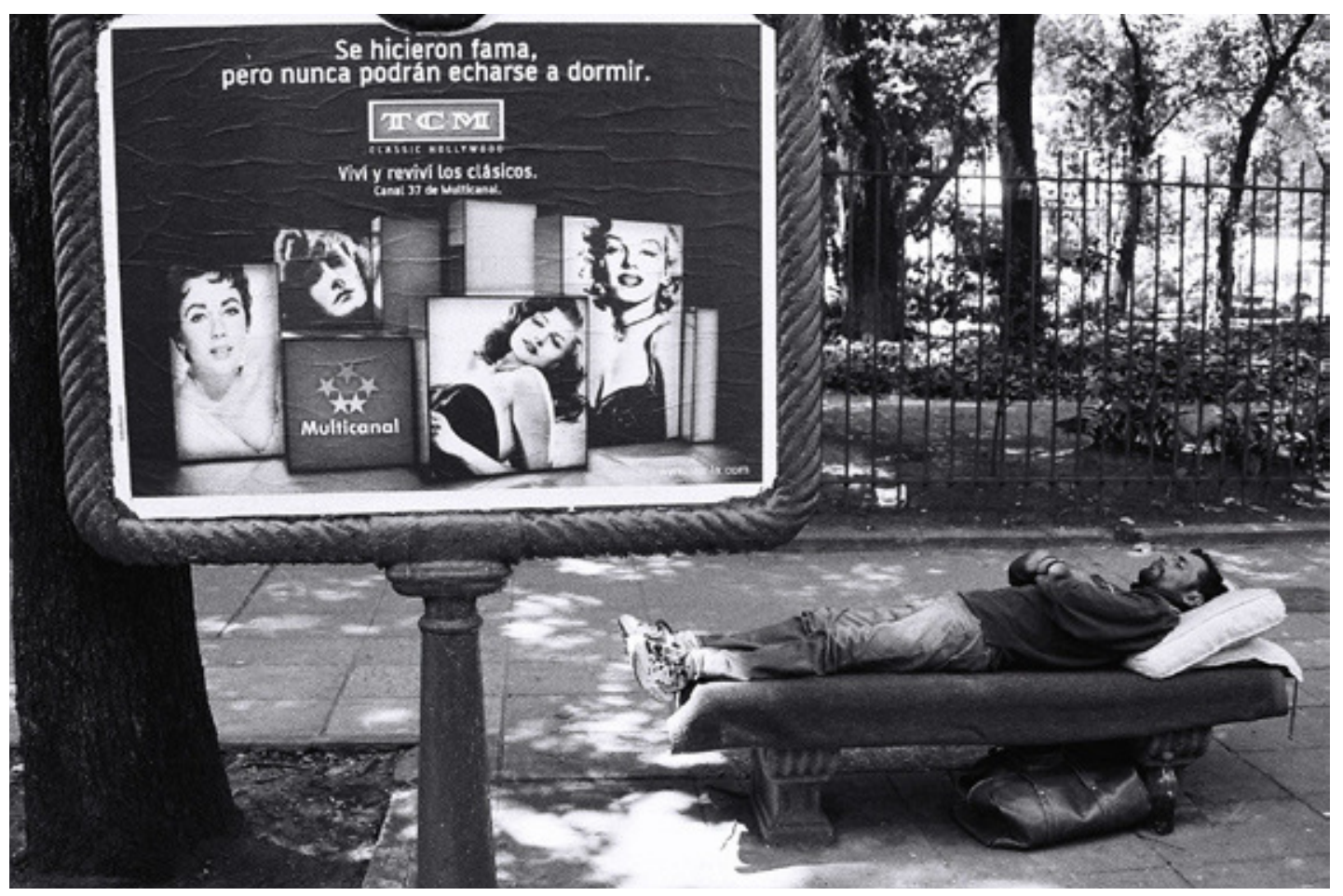

4. Dorminhoco / Buenos Aires-AR

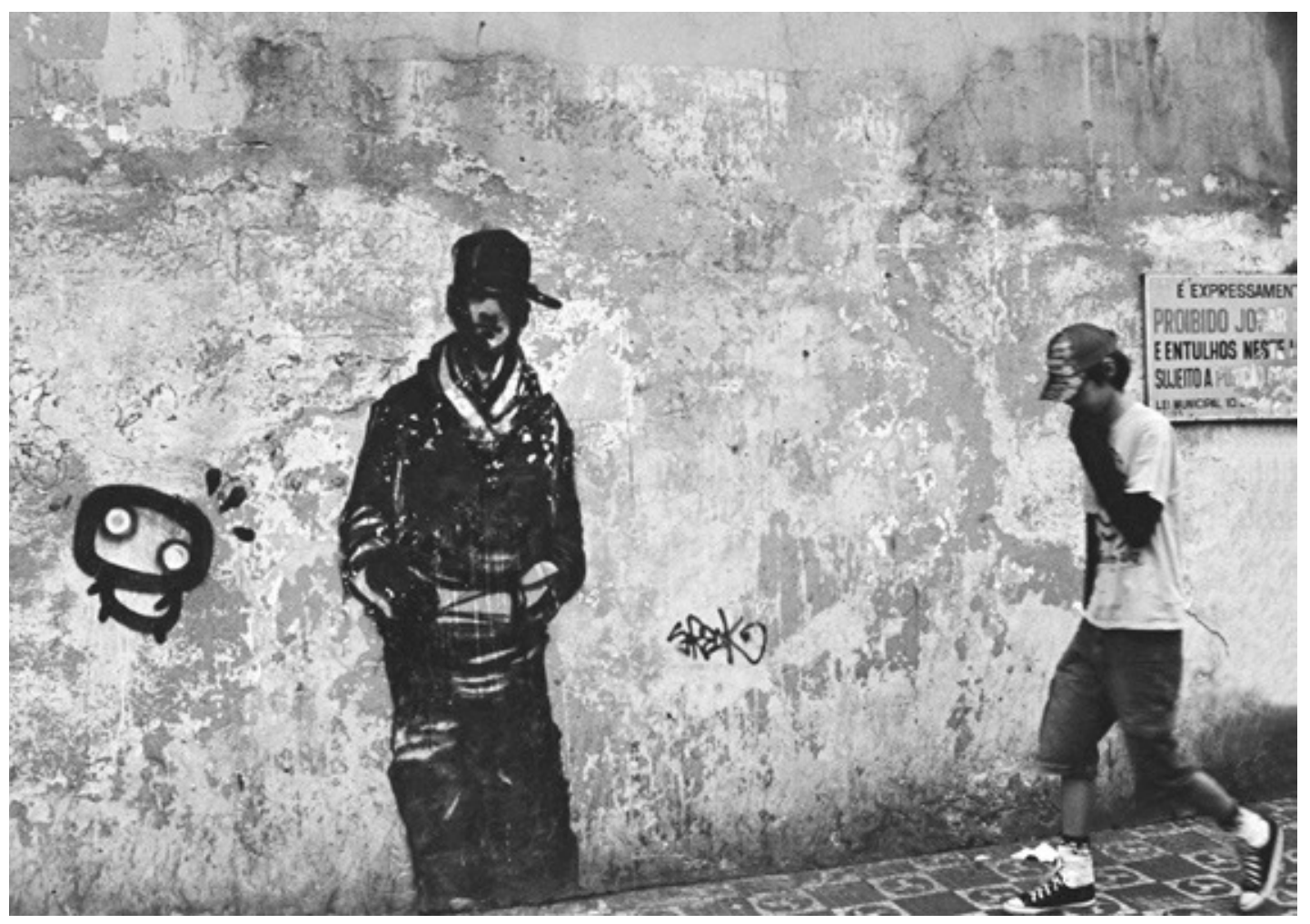

5. Skatistas /São Paulo-SP

cadernos de campo, São Paulo, n. 16, p. 171-175, 2007 
Políticas E POÉTICAS DA VIDA URBana $\mid$ I75

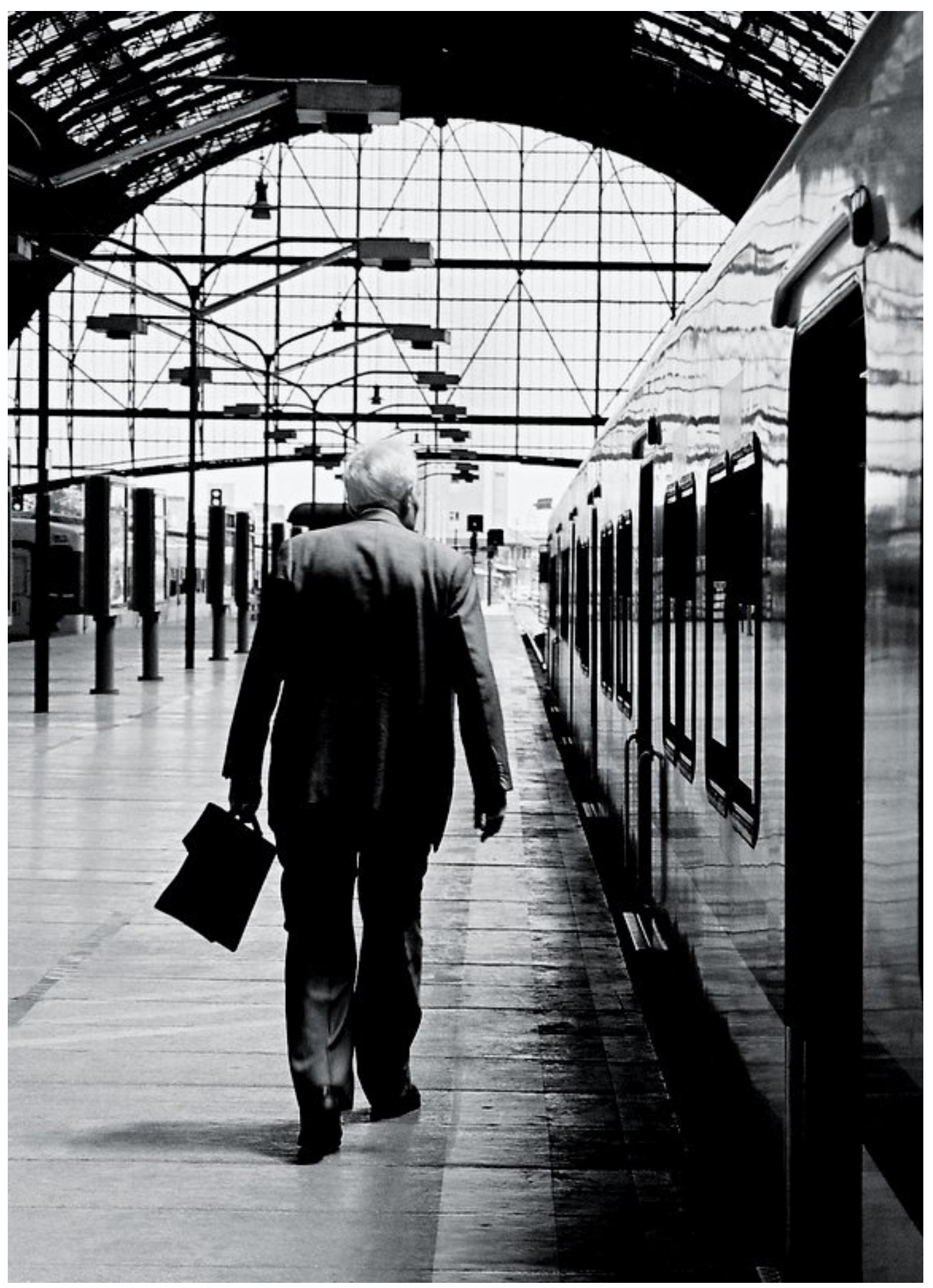

6. Estação / Buenos Aires-AR 